\title{
A produção de roteiros de áudio-descrição de vídeos feita por iniciantes: dificuldades comuns e sugestões para evitá-las
}

\author{
The production of audiodescriptive scripts for videos made by beginners: \\ common difficulties and suggestions to avoid them
}

La producción de guiones de audio-descripción de vídeos hecha por principiantes: dificultades comunes y sugerencias para evitarlas

\author{
Paulo Augusto Almeida Seemann \\ Professor Centro Estadual de Educação Tecnológica Paula Souza, São Paulo, São Paulo, Brasil \\ paasbrsp@yahoo.com.br \\ ORCID: https://orcid.org/0000-0002-2726-3594
}

Recebido em 19 de novembro de 2018

Aprovado em 2 de outubro de 2019

Publicado em 12 de novembro de 2019

\section{RESUMO}

O ensino das técnicas de áudio-descrição (A-D), como modalidade de tradução visual e recurso de acessibilidade, está cada vez mais presente em diversos tipos de cursos: cursos livres, como componente curricular de cursos universitários, cursos de extensão e pós-graduação. É provável que muitos estudantes iniciantes, ao produzir o primeiro roteiro de A-D para vídeos ou filmes, apresentem dificuldades similares. Neste estudo, o objetivo foi detectar dificuldades semelhantes dos alunos principiantes ao produzir o primeiro roteiro de A-D de vídeos, para então oferecer sugestões aos professores de A-D. Foram analisados 49 roteiros do curso Princípios e Técnicas da Audiodescrição: Aplicabilidade em Contextos Culturais Educacionais, promovido pelo Núcleo de Educação a Distância da UNESP e realizado em 2016. Entre as dificuldades mais encontradas, destacam-se: ausência de descrição onde poderia haver; tempo de leitura do texto áudio-descritivo maior do que o tempo disponível no vídeo; uso indevido dos artigos definidos no lugar dos indefinidos e/ou omissão dos indefinidos; interpretações pessoais; uso dos possessivos seu(s), sua(s) e uso desnecessário de linguagem técnica/fílmica. Percebeu-se que grande parte das dificuldades apresentadas pelos estudantes se deve ao fato de eles não terem tido contato suficiente com modelos profissionais de roteiros áudio-descritivos antes de produzirem o primeiro roteiro. A detecção de algumas das dificuldades mais comuns em roteiros de iniciantes em A-D possibilita que futuros cursos e professores, cientes dessas dificuldades, possam trabalhá-las de maneira que elas já não ocorram desde o primeiro roteiro produzido pelos estudantes.

Palavras-chave: Áudio-descrição; Acessibilidade; Inclusão.

\section{ABSTRACT}

The teaching of audio description (AD) techniques, as a visual translation modality and accessibility resource, is increasingly present in several types of courses: free courses, such as curricular component of university courses, extension and postgraduate courses. It is likely that many beginning students, in producing the first AD script for videos or films, 
have similar difficulties. In this study, the goal was to detect similar difficulties for beginning students by producing the first AD script for video, to then offer suggestions to $A D$ teachers. Forty-nine scripts of the Course on Audiodescripts Principles and Techniques: Applicability in Educational Cultural Contexts, promoted by the Nucleus of Distance Education of UNESP and conducted in 2016, were analyzed. Among the most commonly encountered difficulties are: absence of description where there could be; audiodescriptive text reading time greater than the time available in the video; undue use of defined articles in lieu of undefined and/or omission of indefinite articles; personal interpretations; use of ambiguous possessive pronouns and unnecessary use of technical/film language. It was noticed that most of the difficulties presented by the students are due to the fact that they did not have enough contact with professional models of audio descriptive scripts before producing the first script. Detecting some of the most common difficulties in beginning AD scripts makes it possible for future courses and teachers, aware of these difficulties, to work on them so that they no longer occur from the first script produced by the students.

Keywords: Audio description; Accessibility; Inclusion.

\section{RESUMEN}

La enseñanza de las técnicas de audio-descripción (A-D), como modalidad de traducción visual y recurso de accesibilidad, está cada vez más presente en diversos tipos de cursos: cursos libres, universitarios, de extensión y posgrado. Es probable que estudiantes principiantes, al producir el primer guión de A-D para vídeos o películas, presenten dificultades similares. En este estudio, el objetivo fue detectar dificultades similares de los alumnos principiantes al producir el primer guión de A-D de videos, para entonces ofrecer sugerencias a los profesores de A-D. Se analizaron 49 guiones del curso Principios y Técnicas de la Audio-descripción: Aplicabilidad en Contextos Culturales Educacionales, promovido por el Núcleo de Educación a Distancia de la UNESP y realizado en 2016. Entre las dificultades más comúnmente encontradas, se destacan: ausencia de descripción donde podría haber; tiempo de lectura del texto audio-descriptivo mayor que el tiempo disponible en el vídeo; uso indebido de los artículos definidos en lugar de los indefinidos y/o omisión de los indefinidos; interpretaciones personales; uso del posesivo su(s) y uso innecesario de lenguaje técnico/fílmico. Se percibió que gran parte de las dificultades presentadas por los estudiantes se debe al hecho de que no tuvieron suficiente contacto con modelos profesionales de guiones audio-descriptivos antes de producir el primer guión. La detección de algunas de las dificultades más comunes en los guiones de principiantes en A-D permite que futuros cursos y profesores, conscientes de esas dificultades, puedan trabajar de manera que ya no ocurran desde el primer guión producido por los estudiantes.

Palabras clave: Audio-descripción, Accesibilidad, Inclusión.

\section{Introdução}

A áudio-descrição $(A-D)^{1}$ é uma técnica de tradução visual, uma modalidade de tradução intersemiótica (JAKOBSON, 1995), que visa à transformação de imagens e eventos imagéticos em palavras para, principalmente, quem não os pode ver. $A$ A-D foi 
inicialmente pensada para tornar o "mundo visível" acessível às pessoas com deficiência visual. Com o tempo, a $A-D$ se mostrou útil também para pessoas com algum tipo de deficiência intelectual, disléxicos e idosos (MOTTA, 2010, p. 68).

O "público geral" e crianças também podem se beneficiar da A-D, pois ela traz descrições objetivas de aspectos visuais que poderiam passar despercebidos, seja por distração ou por falta de conhecimento específico. Além disso, qualquer pessoa está sujeita a ter um problema visual permanente ou temporário que a empeça de ver.

A A-D não é mera descrição em áudio. É uma tecnologia assistiva e segue critérios específicos que empoderam o público-alvo. A A-D não julga, interpreta ou explica. Ao traduzir imagem em palavras, o objetivo da A-D é o empoderamento de seu público. Empoderar uma pessoa com deficiência visual por meio da A-D significa dar para essa pessoa as mesmas informações visuais relevantes que um vidente recebe ao olhar para algo. A A-D descreve da forma mais objetiva possível o evento imagético, para que a pessoa com deficiência visual possa formar uma imagem mental desse evento e, assim, fazer o seu próprio julgamento.

Segundo os dados do Censo de 2010 do Instituto Brasileiro de Geografia e Estatística (IBGE²), o país tem mais de 500 mil brasileiros cegos, cerca de seis milhões têm baixa visão e aproximadamente 35 milhões declararam ter dificuldade permanente para enxergar, inclusive com o uso de óculos. Todos esses milhões de brasileiros são potenciais beneficiários da A-D.

A A-D pode ser aplicada em praticamente todas as áreas da vida: cinema, televisão, teatro, museus, galerias, eventos diversos, obras de arte, desenhos, fotos, ilustrações, gráficos, mapas etc. A A-D pode ser realizada ao vivo (ensaiada ou simultânea) ou com locução pré-gravada. Conforme Lima (2011, p. 10): "O produto final da tradução do áudiodescritor pode, então, aparecer na forma de uma locução, na impressão Braille da descrição ou em um roteiro áudio-descritivo".

Para a realização específica de uma A-D de filmes e vídeos em geral (longasmetragens, curtas-metragens, séries de TV, documentários, desenhos animados, clipes musicais, comerciais etc.), é necessário produzir um roteiro áudio-descritivo, que precisará ser revisado por um consultor qualificado e com deficiência visual (MIANES, 2016, p. 13), para posteriormente ser locucionado pelo áudio-descritor ou por locutores profissionais. O áudio com a locução gravada é inserido nos momentos em que não há falas no vídeo. 
http://dx.doi.org/10.5902/1984686X35720

$\mathrm{Na}$ produção do roteiro áudio-descritivo, alguns aspectos, regras, princípios ou diretrizes devem ser observados. Embora exista um crescente interesse pela área, ainda não há diretrizes oficiais detalhadas para a confecção de um roteiro áudio-descritivo brasileiro. Em geral, "emprestam-se" os modelos de outros países, entre eles o modelo inglês $^{3}$ (elaborado no ano de 2000), o modelo espanhol ${ }^{4}$ (elaborado em 2005) e as diretrizes norte-americanas da Audio Description Coalition ${ }^{5}$ (elaboradas em 2008).

No Brasil, boa parte dos pesquisadores adota os modelos espanhol e/ou britânico na elaboração de roteiros de AD de filmes [...]. Vale lembrar que a norma britânica sugere um roteiro mais centrado nos detalhes, enquanto a espanhola sugere um roteiro mais centrado nas ações. Há também quem paute seus roteiros pela norma americana - o único modelo com tradução para o português [...]. (MONTE, 2016, p. 97)

Alguns autores sugerem a mescla dos modelos britânico e espanhol para um modelo brasileiro (ALVES; TELES \& PEREIRA, 2011): uma A-D nem tão detalhista e nem tão centrada só em ações. Outros autores propõem a adoção das diretrizes propostas na Audio Description Coalition, que foram traduzidas e adaptadas para o português do Brasil e trazem um bom detalhamento de procedimentos a serem adotados pelos áudiodescritores.

Para este estudo, tomamos como base, principalmente, as diretrizes mencionadas no texto em português da Audio Description Coalition, com tradução e adaptação realizada por Paulo André de Melo Vieira ${ }^{6}$. Entre os princípios apresentados por essas diretrizes, estão: descrever objetivamente e apenas o que pode ser visto; permitir aos usuários ouvir os diálogos e falas; confiar na capacidade de o usuário compreender o que se está áudio-descrevendo; permitir que o próprio material forneça as informações para os ouvintes; não censurar informação relevante; usar uma linguagem consistente; não dizer etnicidade e nacionalidade, mas sim, descrever cor de pele e outros traços físicos; descrever a partir da perspectiva dos ouvintes.

Também consideramos as sugestões dadas pelo pesquisador e professor Francisco Lima, em seus artigos Introdução aos Estudos do Roteiro para Áudio-Descrição: Sugestões para a Construção de um Script Anotado (2011) e Áudio-Descrição: Orientações para uma Prática sem Barreiras Atitudinais (LIMA; GUEDES \& GUEDES, 2010). Neste último, os autores chamam a atenção para atitudes que o áudio-descritor deve evitar ter ao produzir um roteiro. São as barreiras atitudinais, cujas principais são:

1. Padronização: não se deve presumir que todos os usuários da $A-D$ sejam iguais. Alguns podem preferir A-Ds com mais detalhes, outros com menos; 
http://dx.doi.org/10.5902/1984686X35720

2. Piedade: o áudio-descritor não deve fazer explicações e interpretações pessoais que deixem o entendimento mais "fácil";

3. Estereótipos: não deve o áudio-descritor fazer generalizações em torno do tipo de deficiência do público-alvo;

4. Compensação: o áudio-descritor não deve querer compensar o público com deficiência com informações que não estão disponíveis aos demais.

De acordo com Lima (2011, pp. 13-14), um roteiro áudio-descritivo de qualidade deve conter: concisão (o mínimo de palavras e/ou caracteres com o máximo de informação); clareza (o texto deve ser bem nítido, compreensível); correção (a exatidão com que se áudio-descreve); especificidade (escolha tradutória de palavras e termos que reflete a melhor e mais precisa ideia do que se está áudio-descrevendo); vividez (escolha tradutória que deixa a mais vívida imagem na mente do público-alvo); notas proêmias (antecedem a A-D e trazem informações técnicas da obra, como autor, tema, ano de produção, definição de termos usados na A-D etc.).

Em vídeo ou filme, as notas proêmias também podem trazer descrições de personagens, cenários e tudo mais que não seja possível descrever durante a execução da obra. Porém, é preciso tomar cuidado para não antecipar informações que, por exemplo, façam parte de algum "suspense" na trama.

Lima (2011, pp. 22-25) também sugere diretrizes para o roteiro da A-D: redigir na terceira pessoa do presente do indicativo; evitar expressões como "nós vemos"; evitar o uso de termos fílmicos; evitar os pronomes possessivos seu(s), sua(s); descrever sem usar conjunções adversativas; utilizar artigos definidos para algo já mencionado e os indefinidos para algo que se menciona por primeira vez; observar as regras de coesão e coerência; procurar usar frases completas etc.

Também nos baseamos em algumas recomendações dadas por Naves (2015, pp. 10-11), a qual orienta que os roteiros de A-D de produções audiovisuais tragam as marcações de tempo para a inserção da locução áudio-descritiva com, se necessário, observações ou instruções pontuais para o locutor. A voz do locutor deve ser preferencialmente colocada entre diálogos ou nos momentos em que não haja som relevante para o entendimento da trama.

Nos últimos anos no Brasil, vêm surgindo cada vez mais cursos de A-D. São cursos livres, de extensão ou A-D como componente curricular de alguma grade de curso 
http://dx.doi.org/10.5902/1984686X35720

universitário: graduação e/ou pós-graduação. Muitas pessoas começam a produzir seus primeiros roteiros áudio-descritivos nesses cursos.

Contudo, na primeira produção de um roteiro por alunos iniciantes em A-D, é possível que algumas dificuldades sejam mais frequentes e, por isso, requeiram uma atenção maior por parte dos próprios alunos e também de seus professores. Com a identificação prévia e a ciência dessas dificuldades em comum, cursos de áudiodescrição, seus professores e tutores, ou mesmo, estudantes autodidatas de A-D podem tomar as providências necessárias para que o primeiro roteiro de A-D em vídeo produzido já não apresente tais dificuldades.

\section{Objetivo}

O objetivo deste estudo é identificar e divulgar as dificuldades mais comuns apresentadas em roteiros de A-D de vídeo produzidos por estudantes (e profissionais iniciantes), e também oferecer sugestões para evitá-las ou amenizá-las ao se produzir o primeiro roteiro áudio-descritivo, seja no contexto educacional, seja no contexto profissional.

\section{Metodologia}

Para tanto, identificamos e analisamos as dificuldades encontradas no primeiro roteiro de A-D de vídeo produzido por alunos do curso Princípios e Técnicas da Audiodescrição: Aplicabilidade em Contextos Culturais Educacionais, promovido pelo Núcleo de Educação a Distância da Universidade Estadual Paulista Júlio de Mesquita Filho - UNESP.

O curso ocorreu no segundo semestre de 2016, ofertado na modalidade "a distância", em Ambiente Virtual de Aprendizagem (AVA) e com uma carga horária total de 180 horas, divididas em sete módulos.

Todos os módulos tiveram um vídeo introdutório, no qual a professora do curso, profissional de A-D, explica e dá exemplos teóricos e práticos dos temas abordados no módulo, além de haver textos de apoio. Os tutores, com experiência em A-D, esclareciam as dúvidas dos alunos, avaliavam as atividades realizadas e forneciam os feedbacks correspondentes com os apontamentos das dificuldades e sugestões de aprimoramentos.

O primeiro contato que os alunos principiantes em A-D tiveram com produção de um roteiro áudio-descritivo de vídeo/filme dentro do curso foi no quinto módulo. Em uma das 
atividades desse módulo, o aluno deveria fazer a A-D de um vídeo (apenas o roteiro, não a locução). Na plataforma do AVA, havia a sugestão de três vídeos disponíveis no Youtube, mas o aluno também poderia escolher algum outro vídeo.

O primeiro vídeo sugerido tem três minutos de duração. Intitulado "Feliz Natal Grupo Zaffari”", o áudio não contém falas, somente música de fundo. O segundo vídeo sugerido tem um minuto e meio de duração. Intitulado "Doação de órgãos - A campanha que está emocionando o mundo"8, o áudio do vídeo tampouco tem falas, apenas uma trilha sonora. O terceiro vídeo sugerido tem dois minutos e quarenta segundos de duração. Intitulado "Lisboa apela à adoção de animais"9, o vídeo é uma reportagem, havendo vários depoimentos e falas em off, mas com alguns momentos em que o áudio tem somente uma trilha sonora, sendo esses os momentos propícios para a inserção da A-D.

No vídeo introdutório do quinto módulo, a professora responsável comenta sobre as A-Ds de imagens estáticas e imagens dinâmicas gravadas e ao vivo. Instrui que, em vídeos, o texto da A-D é limitado pelas falas do próprio vídeo e por sons relevantes, devendo-se evitar a sobreposição da voz do locutor da A-D nesses momentos. São também explicados a minutagem (ou time-code), as deixas e os comentários (rubricas) nos roteiros de A-D. Nos módulos anteriores, já se havia comentado sobre a presença de notas proêmias nos roteiros áudio-descritivos. As notas proêmias deveriam estar presentes na produção do roteiro de vídeo da atividade do quinto módulo.

Na página da atividade, havia instruções para a confecção de roteiro áudio-descritivo para vídeos, com informações adicionais e reforço do que já se havia falado no vídeo introdutório do módulo. Também havia um link para um periódico que comenta a A-D de um filme, com exemplos de trechos do roteiro áudio-descritivo.

A atividade do curso pedia que os alunos enviassem em arquivo de Word o roteiro áudio-descritivo de um dos vídeos sugeridos ou de qualquer outro vídeo disponibilizado no Youtube. Posteriormente, os tutores deram o feedback, que consistiu em fornecer orientações para o aperfeiçoamento do roteiro. Por se tratar de um primeiro roteiro de A-D para vídeos, o feedback dado se concentrou nas dificuldades mais básicas de estrutura, redação, adequação do texto ao tempo disponível nas cenas e nos trechos sem falas ou sons relevantes do vídeo e nos aspectos descritivos mais importantes para 0 entendimento da obra. 
http://dx.doi.org/10.5902/1984686X35720

De acordo com Naves (2015, pp. 10-11), os roteiros áudio-descritivos de filmes ou programas de TV precisam trazer os tempos iniciais e finais das inserções da A-D, as deixas (a última fala antes de entrar a $A D$ ) e as rubricas (instruções para a locução da AD). A locução com as descrições deve ser colocada preferencialmente entre diálogos, podendo estar ligeiramente adiantada ou atrasada. A locução da A-D não deve se sobrepor à trilha sonora, falas e sons importantes para a compreensão do enredo, exceto quando a informação visual for mais importante que a sonora.

Embora dois dos vídeos sugeridos não tivessem diálogos, havia música de fundo. Neles, a música reforça o aspecto emocional da trama. É impossível fazer a A-D desses vídeos sem sobrepor a locução à música. No entanto, entre outros aspectos, levou-se em consideração se os roteiros deixariam alguns espaços para a música ser ouvida sem a interferência da $A-D$; se os alunos teriam a sensibilidade de perceber que a música também tem importância e deveria juntar-se a A-D, e não ser completamente anulada por ela.

Foram coletados os roteiros individuais de um grupo de alunos sob uma mesma tutoria e os respectivos feedbacks do tutor; alunos que declararam nunca ter feito roteiros de A-D. Nos feedbacks, as dificuldades encontradas nos roteiros foram apontadas pelo tutor. Assim, os feedbacks já fornecem quantas e quais dificuldades cada roteiro apresenta. Os roteiros coletados serviram para posterior verificação e revisão das dificuldades mencionadas nos feedbacks.

Além de apontar as dificuldades, os feedbacks também esclarecem dúvidas específicas do aluno e trazem sugestões de aprimoramento. Para este estudo, na análise dos feedbacks, centramo-nos exclusivamente nas dificuldades identificadas, pois a nossa intenção é oferecer sugestões para que, em futuros cursos de A-D, a ocorrência de tais dificuldades possam ser evitadas já na primeira produção de um roteiro de A-D para vídeos.

Constatamos um total de 49 roteiros produzidos por alunos principiantes: 29 roteiros do vídeo Doação de órgãos, o mais curto entre os vídeos sugeridos; nove roteiros do vídeo Feliz Natal; sete roteiros do vídeo Lisboa apela à adoção de animais; e quatro roteiros de outros vídeos disponibilizados no Youtube. Os 49 feedbacks enviados para os alunos foram (re)lidos e as dificuldades apontadas pelo tutor foram contadas e agrupadas no seguinte quadro: 
http://dx.doi.org/10.5902/1984686X35720

Quadro 1 - dificuldades encontradas nos roteiros dos alunos iniciantes em A-D do curso Princípios e Técnicas da Audiodescrição: Aplicabilidade em Contextos Culturais Educacionais - UNESP - 2016

\begin{tabular}{|c|c|}
\hline TIPO DE DIFICULDADE & $\begin{array}{l}\text { QUANTIDADE DE ROTEIROS QUE APRESENTARAM } \\
\text { A DIFICULDADE }\end{array}$ \\
\hline $\begin{array}{l}\text { Dificuldades gerais com a estrutura do } \\
\text { roteiro }\end{array}$ & $\begin{array}{l}24 \text { roteiros: } 9 \text { (A-D, deixas e rubricas confusas, trocadas } \\
\text { ou misturadas); } 8 \text { (ausência do tempo de saída); } 4 \\
\text { (sobreposição da A-D às falas); } 3 \text { (sem marcação de } \\
\text { tempo); } 1 \text { (sem marcação de tempo nos créditos finais do } \\
\text { vídeo); } 1 \text { (marcações de entrada e saída "grudadas") }\end{array}$ \\
\hline $\begin{array}{l}\text { Dificuldades específicas nas notas } \\
\text { proêmias }\end{array}$ & $\begin{array}{l}9 \text { roteiros: } 5 \text { (revelam demais), } 2 \text { (pouca informação); } 2 \\
\text { (informação desnecessária). }\end{array}$ \\
\hline $\begin{array}{l}\text { Ausência de descrição onde poderia } \\
\text { haver }\end{array}$ & $\begin{array}{l}38 \text { roteiros: } 28 \text { (ausência de descrição física de } \\
\text { personagens principais); } 10 \text { (ações relevantes não } \\
\text { descritas) }\end{array}$ \\
\hline Correção e especificidade & 7 roteiros \\
\hline Interpretações/deduções pessoais & $\begin{array}{l}22 \text { roteiros: } 10 \text { ("dono"); } 6 \text { ("jardineiro"); } 5 \text { ("pai”, "mãe" } \\
\text { e/ou "filha"); } 2 \text { ("amigos"); } 4 \text { (outros problemas de } \\
\text { interpretação pessoal) }{ }^{11}\end{array}$ \\
\hline $\begin{array}{l}\text { Tempo de leitura do texto áudio- } \\
\text { descritivo é maior do que o tempo } \\
\text { disponível no vídeo }\end{array}$ & 38 roteiros \\
\hline $\begin{array}{l}\text { Descrição de cena em um novo cenário } \\
\text { sem começar pela citação do cenário }\end{array}$ & 29 roteiros \\
\hline $\begin{array}{l}\text { Uso desnecessário de linguagem } \\
\text { técnica/fílmica }\end{array}$ & $\begin{array}{l}15 \text { roteiros: } 6 \text { "(câmera”); } 3 \text { ("close”); } 3 \text { ("foco"); } 2 \\
\text { ("primeiro plano"); } 1 \text { ("troca de tela"); } 1 \text { ("outro cenário"); } 1 \\
\text { ("câmera foca"); } 1 \text { ("imagem foca"); } 1 \text { ("corte"); } 1 \\
\text { ("transição de vídeo") })^{12}\end{array}$ \\
\hline Frases muito longas & 6 roteiros \\
\hline 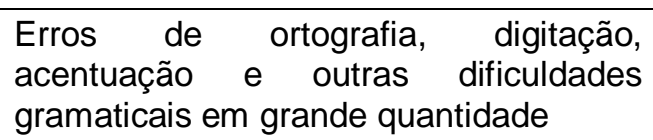 & 7 roteiros \\
\hline Uso de conjunção adversativa & 7 roteiros \\
\hline Uso dos possessivos seu(s), sua(s) & 16 roteiros \\
\hline $\begin{array}{llll}\begin{array}{l}\text { Ambiguidade } \\
\text { possessivos) }\end{array} & \text { (sem } & \text { considerar } & \text { os } \\
\end{array}$ & 3 roteiros: 2 (“ele/ela"); 1 (outro tipo de ambiguidade) \\
\hline $\begin{array}{l}\text { Uso indevido dos artigos definidos no } \\
\text { lugar dos indefinidos e/ou omissão dos } \\
\text { artigos indefinidos }\end{array}$ & $\begin{array}{l}27 \text { roteiros: } 25 \text { (uso dos definidos no lugar dos } \\
\text { indefinidos); } 2 \text { (ausência de artigos) }\end{array}$ \\
\hline
\end{tabular}

Fonte: própria. 
http://dx.doi.org/10.5902/1984686X35720

\section{Análise dos resultados ${ }^{13}$}

Embora não haja um formato oficial para um roteiro de áudio-descrição de vídeo, espera-se que o roteiro esteja confeccionado de forma a ficar claro os momentos do vídeo em que o texto da A-D precise ser locucionado e inserido (com as marcações dos tempos de entrada e saída: a minutagem). As informações adicionais (deixas e rubricas), se forem adicionadas, necessitam estar bem claras e separadas dos textos áudio-descritivos.

Como pode ser observado no Quadro 1, dos 24 roteiros com dificuldades na estrutura, a falta de marcação do tempo de saída na minutagem ocorreu em oito roteiros. O texto da áudio-descrição demarcado para ser inserido em momentos do vídeo em que havia falas apareceu em quatro roteiros. Esse número pode parecer baixo, no entanto, entre os vídeos sugeridos na atividade, apenas um dos vídeos continha falas e somente sete alunos o escolheram para fazer o roteiro áudio-descritivo. Também encontramos três roteiros sem marcação de tempo (entrada e saída); um roteiro sem marcação de tempo apenas no momento dos créditos finais do vídeo; um roteiro cujos tempos de entrada e saída estavam "grudados", dificultando a visualização; e nove roteiros em que deixas, rubricas e áudio-descrição estavam confusas, mescladas entre si e/ou trocadas.

Uma possibilidade de formatar um roteiro áudio-descritivo, sugerida nas instruções da atividade, é dividir a página em duas colunas: uma coluna mais estreita à esquerda para a marcação dos tempos de entrada e saída do vídeo em que haverá locução de A-D; a outra coluna, à direita, para receber o texto da $A-D$ correspondente à minutagem, com as observações (deixas e rubricas) que forem necessárias.

Um contato maior dos alunos com modelos de roteiros também pode ajudá-los na hora de produzir o primeiro roteiro. Além disso, numa primeira atividade de produção de roteiro de A-D de vídeo em um curso, talvez a atividade pudesse já trazer pronto um arquivo de documento de Word com a estrutura do roteiro formatada: as duas colunas, com indicação exata de onde vão minutagem, deixa, rubrica e A-D.

Apenas oito alunos puseram no roteiro o tempo de entrada. Porém, havendo os tempos de entrada e de saída, fica bem claro qual é o tempo total que haverá para inserir a A-D no trecho selecionado e, assim, o áudio-descritor saberá o quanto pode ou não se aprofundar nas descrições para aquele momento do vídeo, com textos que possam ser lidos dentro dos tempos estipulados nas minutagens.

Em nove roteiros, houve confusão entre rubrica, deixa e A-D. A deixa é o último som que há no vídeo antes da inserção de uma A-D da cena. Pode ser o final de uma fala, um 
http://dx.doi.org/10.5902/1984686X35720

grito, som de telefone etc. A deixa serve para indicar e reforçar o momento exato do vídeo em que determinada $A-D$ deverá ser inserida. A rubrica é qualquer comentário que e o áudio-descritor ache necessário acrescentar ao roteiro: alguma instrução para o locutor e/ou para o editor que fará a inserção da A-D locucionada no vídeo. Para informações adicionais e mais detalhadas sobre rubricas e deixas, indicamos o já citado texto de Lima (2011).

Ao colocar na mesma coluna a deixa, a áudio-descrição e a rubrica, é preciso que a separação entre as três esteja clara. O uso de cores diferentes, proposta presente nas instruções da atividade do curso, é uma possibilidade. Por exemplo: azul para as deixas, preto para o texto da A-D e vermelho para as rubricas.

Dos nove roteiros com dificuldades encontradas nas notas proêmias, havia cinco roteiros que revelavam demais a trama, que antecipavam coisas que só seriam descobertas pelo público no final da história. Em dois roteiros, havia pouca informação técnica (apenas o nome do vídeo) e em outros dois roteiros havia descrições que também constavam no texto da A-D e, portanto, desnecessárias nas notas. Segundo Lima (2011, p. 14), as notas proêmias antecedem, apresentam e também instruem a própria áudiodescrição. Assim, as notas proêmias podem trazer informações técnicas do vídeo que sejam relevantes: ano de produção, autores (diretor, produtor, roteirista), se recebeu algum prêmio, se há algum ator renomado ou alguma participação especial de pessoa famosa, o estilo do vídeo, uma breve sinopse etc.

Nesses nove roteiros com dificuldades específicas nas notas proêmias, tampouco havia a informação de como e onde elas deveriam ser inseridas no vídeo. Por exemplo, pode-se aproveitar o primeiro ou os primeiros segundos do próprio vídeo e pausá-lo para, então, inserir a locução da A-D na imagem "congelada". Ou, mais comum, deixar a tela preta antes do início do vídeo e, nessa tela preta (ou de qualquer outra cor ou com alguma imagem), inserir a locução da A-D. Também se pode acrescentar, além da locução, o texto da A-D em caracteres sobre a tela preta. Essas sugestões foram apresentadas no curso.

Por se tratar de uma atividade de curso, um exercício, é possível que alguns alunos tenham achado desnecessário informar a forma como as notas proêmias devessem ser inseridas no vídeo. Mas também é possível que os alunos não soubessem como colocar esse tipo de informação no roteiro. Na tutoria desses alunos, não se previu tal dificuldade e, portanto, a questão não foi suficientemente discutida. 
http://dx.doi.org/10.5902/1984686X35720

Consideramos "ausência de descrição onde poderia haver" as descrições ausentes no roteiro que, se estivessem presentes, contribuiriam de forma fundamental para um melhor entendimento da trama, ou seja, descrições relevantes, e também descrições não tão cruciais para o entendimento, mas bastante significativas. Por exemplo, a ausência de descrição física com um mínimo de detalhes (idade aproximada, cor de pele, vestuário) de personagens principais dos vídeos ocorreu em 28 roteiros. Provavelmente, essa ausência teve a influência da falta de tempo disponível do vídeo nos momentos em que os personagens aparecem: muitos alunos, corretamente, privilegiaram as ações (mais relevantes) em detrimento das descrições dos personagens. Porém, a atividade pedia o uso de notas proêmias. Uma das finalidades das notas proêmias, como já salientamos, é exatamente essa: descrever antecipadamente o que não será possível durante o vídeo, devido à falta de tempo disponível.

A leitura de várias notas proêmias como modelos a serem seguidos pode ajudar o iniciante a perceber melhor quais informações as notas podem ou não trazer.

Em outros dez roteiros, algumas ações consideradas relevantes pelo tutor não foram descritas, mas havia tempo para descrevê-las no instante em que a cena acontecia. Isso sugere que o aluno não considerou ou não percebeu a ação como relevante.

Diante de uma cena que precise ser áudio-descrita, o aluno áudio-descritor poderia fazer-se algumas perguntas para decidir o que deve ser descrito. Por exemplo: o que há de imprescindível na cena que deva ser descrito para que haja a compreensão do enredo pelo público-alvo da A-D? O que é razoavelmente relevante na cena, mas não tão imprescindível ao entendimento? O que não é relevante, mas seria interessante descrever? O que é totalmente ou quase totalmente irrelevante para o entendimento e que só valeria a pena descrever se o tempo permitir? Ou seja, sugerimos que o áudiodescritor principiante (ou não) faça uma espécie de hierarquia de relevância e, dentro do tempo disponível, descreva priorizando o que for mais relevante para o entendimento da obra.

Em sete roteiros, foram encontradas dificuldades mais pontuais com relação à correção e especificidade. Em um dos roteiros, por exemplo, a áudio-descrição menciona três pessoas num determinado ambiente, mas só havia duas pessoas. Em outro roteiro, foi mencionada uma "briga braçal", porém, não houve contato físico entre os envolvidos na briga. Em outro, a áudio-descrição menciona que um dos personagens observa outro personagem por um vidro. Mas que vidro? O vidro de uma janela, de uma vitrine? 
http://dx.doi.org/10.5902/1984686X35720

Nesses casos muito específicos, é preciso que o aluno áudio-descritor reveja o material com atenção e revise as suas escolhas tradutórias. Um consultor provavelmente indicaria a questão do "vidro" sem identificação, sem especificidade. Já o fato de haver numa cena menos pessoas do que o mencionado na $A-D$ e uma luta braçal que não se concretizou, um consultor cego não teria como perceber. Por esse motivo, há quem sugira que, numa equipe de áudio-descrição, além de locutor, consultor e áudio-descritor, haja também um revisor vidente do roteiro de A-D. De certa forma, no curso, o papel do tutor equivaleu a esse revisor.

Por mais que uma descrição tente ser objetiva, certo grau de subjetividade estará sempre presente: seja, entre outros, pela escolha lexical do áudio-descritor, seja pelos elementos imagéticos que se considere ou não relevantes na seleção do que será áudiodescrito. Não existe neutralidade em roteiros de A-D (OLIVEIRA JUNIOR \& PRAXEDES FILHO, 2016).

Contudo, a A-D deve tentar descrever da forma mais objetiva possível, com o mínimo de deduções ou interpretações pessoais. Entre os 29 roteiros em que se detectou esse tipo de dificuldade, houve casos muito pontuais e específicos. No vídeo Doação de órgãos, é mostrado o convívio amistoso de um idoso e um cão. Em dez roteiros, o idoso foi mencionado como "dono" do cão. Isso é algo que deduzimos ao assistir às cenas de convívio entre os dois. Mas não poderia o idoso ser alguém que toma conta do cão enquanto os donos viajam? Caberia, portanto, ao áudio-decritor descrever as cenas de convívio e deixar que o público-alvo chegasse à sua própria dedução. Além disso, a unidade lexical "dono" traz uma carga semântica que denota "posse", o que consideramos um pouco inadequado para um vídeo, cujo tipo de relação que há entre seus personagens principais, idoso e cão, é o de amizade.

Ainda nesse vídeo, há uma cena em que o idoso entra em uma lanchonete e passa algum tempo conversando alegremente com outros dois homens. Em dois roteiros, esses homens foram descritos como "amigos". Repetimos a lógica anterior: o ideal seria apenas descrever a cena, sem deduções pessoais, e deixar que o público conclua se os homens são ou não amigos.

No outro vídeo sugerido, Feliz Natal, um homem aparece constantemente cuidando de um jardim de uma praça pública. Ele se comunica visualmente com uma menina fisicamente debilitada que aparece na janela de um apartamento em frente à praça. Dos nove roteiros desse vídeo, em seis deles, o homem foi mencionado como "o jardineiro". 
Mas seria mesmo um jardineiro profissional contratado exclusivamente para cuidar da praça? Ou seria um homem que mora próximo e gosta de cuidar das plantas e flores da praça como hobby? As descrições de vestuário, acessórios (as ferramentas de jardinagem) e as ações do homem podem dar condições suficientes para que o públicoalvo da A-D chegue a sua própria conclusão.

Nesse mesmo vídeo, em alguns momentos, uma mulher aparece com a menina e, posteriormente, outro homem também aparece junto com a mulher. Em cinco roteiros, mulher, homem e/ou menina são citados como "mãe", "pai" e/ou "filha". Mas não poderia a mulher ser uma tia que cuida da sobrinha porque a mãe da menina já falecera? E o homem não poderia ser um padrasto, um tio da menina ou um namorado da mulher? Pelo enredo do vídeo, ou seja, pela descrição das ações, podemos deduzir que esses três personagens sejam uma família, mais provavelmente: mãe, pai e filha. Porém, cabe ao áudio-descritor descrever; cabe ao público-alvo deduzir.

Sabemos que, dependendo da concepção de A-D que se tenha ou das diretrizes e princípios adotados, o que chamamos acima de "dificuldades", para alguns profissionais da A-D seriam apenas "estratégias tradutórias". Contudo, visando o empoderamento do público-alvo, sugerimos que a descrição (de cenas e personagens) seja feita da forma mais objetiva possível, evitando as interpretações pessoais e deixando que o público-alvo chegue a sua própria conclusão. É preciso confiar na capacidade de o usuário da A-D entender o material.

Outra dificuldade com alto índice de ocorrência, detectada em 38 roteiros, são os textos áudio-descritivos que não cabem no tempo determinado. Por exemplo, em alguns roteiros, a minutagem marcava algo como "00:00:20 - 00:00:23" (tempo de entrada: 20 segundos; saída: 23 segundos) e era acompanhada por um texto de A-D com várias linhas de extensão; um texto que só poderia ser lido num espaço de tempo com (muito) mais do que os 3 segundos disponíveis. A maioria dos roteiros dos dois vídeos sem diálogos também não continha espaço algum para as músicas de fundo se sobressaírem. Nesses roteiros, o tempo de leitura de todos os trechos com A-D superava o tempo total do vídeo.

Uma vez feita toda a minutagem no roteiro (marcação dos tempos de entrada e saída de todos os momentos do vídeo em que é possível colocar a locução da A-D), ao escrever o texto da A-D a ser locucionado, o aluno deve ter à mão algum relógio ou cronômetro, para que leia em voz alta o texto e, dessa forma, saiba se ele caberá no 
espaço de tempo determinado. O uso do programa Subtitle Workshop também é uma boa opção, pois, embora seja um programa criado para fazer legendas, ele ajuda o áudiodescritor a perceber se a leitura do texto da A-D não superará o tempo disponível no trecho selecionado do vídeo.

Conforme já mencionado, a minutagem para vídeos com diálogos deve levar em consideração os momentos sem falas ou sons importantes. Nos dois vídeos sugeridos sem diálogos, uma possibilidade de fazer a minutagem seria separar por cenas (ou cenários): entre as cenas, alguns segundos sem A-D, para que a música de fundo possa também ser apreciada.

Em vídeo (filmes, séries, desenhos animados etc.), toda vez que há uma mudança de cenário, o ideal seria que a A-D iniciasse o texto citando o novo lugar em que a cena acontece. Dos 49 roteiros, apenas 20 iniciaram os textos pelo cenário. Houve, inclusive, em alguns momentos de alguns roteiros, uma completa omissão de cenário. Mas o mais comum foi o cenário ser mencionado no final das frases. Começar o texto da A-D pelo lugar em que a cena acontece contribui para que o público-alvo "se localize" no enredo. Não se trata de uma regra rígida, mas de uma sugestão, que pode ajudar o público da A$\mathrm{D}$ do vídeo a construir mais facilmente a imagem mental da cena áudio-descrita.

Há profissionais que defendem o uso de linguagem fílmica nos roteiros de A-D para vídeos/filmes. Mas também há profissionais que criticam esse uso, devendo o áudiodescritor mencionar a sensação que determinado recurso técnico causa no espectador, em lugar de nomear o recurso. Para estes, os termos técnicos/fílmicos podem não ser do conhecimento do público-alvo da $A-D$, além de romperem, em certa medida, com a fruição do texto áudio-descritivo ("vivacidade"). "O uso de termos como 'a câmera se afasta', 'close', etc., dificulta a compreensão de cenas se o deficiente visual não está acostumado aos termos da linguagem cinematográfica" (ALVES; TELES \& PEREIRA, 2011, p. 24). Assim, acreditamos que a linguagem técnica ou fílmica deva ser evitada sempre que possível.

Evitar a linguagem técnica não significa omitir a descrição do recurso tecnológico usado em uma cena. Por exemplo, uma coisa é um personagem fazer algo lentamente, outra coisa é o personagem fazer algo em velocidade "natural", mas com a velocidade dessa ação diminuída por meio de recurso tecnológico. É a popular "câmera lenta". Há casos em que, durante um filme (série de TV, desenho animado etc.), aparecem dois 
cenários juntos, divididos na tela. Um exemplo típico disso são as cenas em que duas pessoas conversam por telefone e as duas são mostradas ao mesmo tempo.

Dessa forma, se não se consegue descrever a sensação que determinado recurso tecnológico causa no espectador, pode-se descrever o que o recurso faz, sem necessariamente nomeá-lo, pois nem todos sabem o que é um slow motion ou wipe (fade in, fusão, corte seco etc.).

Neste estudo, consideramos como "dificuldade", quando a linguagem fílmica ou técnica encontrada no roteiro dos alunos poderia facilmente ser evitada ou trocada por palavras ou expressões mais popularmente usadas no cotidiano. Dos 15 roteiros com esse tipo de dificuldade, em seis houve a menção desnecessária de "câmera". Foram ocorrências como: "olha para a câmera", "câmera desce" e "câmera se afasta". A "câmera" poderia ser citada quando ela realmente estivesse visível (e fosse relevante) em uma cena; quando ela fizesse parte do cenário. O "olha para câmera" apareceu em 3 (três) roteiros. Conforme sugere a Audio Description Coalition ${ }^{14}$, em A-D de vídeos ou filmes, descreve-se: “[...] 'o tubarão nada em nossa direção,' não 'o tubarão nada em direção à câmera' ou 'nós nos movemos através da floresta' em vez de 'a câmera se move através da floresta.".

Os outros termos fílmicos que apareceram foram: "close", "foco", "troca de tela", "outro cenário", "transição de vídeo", "primeiro plano", "imagem/câmera foca", "corte”. Nos roteiros analisados em que apareceram "primeiro plano", "close", "foco", "câmera/imagem foca", esses termos podiam ser simplesmente omitidos, sem prejuízo para o entendimento da cena. O "corte", "troca de tela", "transição de vídeo", "outro cenário" referem-se a uma mudança de cena/cenário no vídeo. A simples descrição do novo cenário já seria suficiente. Em uma mudança mais brusca de cenário ou que possa haver alguma confusão entre o cenário anterior e o novo cenário, "às vezes um áudio-descritor pode usar a palavra 'agora' para indicar uma mudança de cena no meio de um segmento de descrição"15. Exemplo hipotético: "Na sala, Maria senta-se no sofá. Agora, numa rua ensolarada, Maria anda apressada".

Uma das características mais desejáveis em uma A-D é a concisão. "O audiodescritor edita o que vê, ou seja, seleciona o que é mais importante para a compreensão e a apreciação de um evento." (ALVES; TELES \& PEREIRA, 2011, p. 23). Em seis roteiros, apareceram frases áudio-descritivas muito longas. 
Embora não haja um limite para a frase numa A-D, quanto menor for, maior será a possibilidade de apreensão por parte do público. As frases longas encontradas nos roteiros dos alunos poderiam facilmente ser transformadas em duas, três ou quatro frases mais curtas. O problema maior estava simplesmente na pontuação. Não estavam longas por excesso de informação, mas sim, por haver vírgula(s) onde poderia ou deveria haver um ponto final. Em alguns casos, a sentença mais extensa continha oração subordinada. Conforme Naves (2015, p. 14): "[...] quanto à complexidade sintática, recomenda-se o uso de orações coordenadas, sem muita complexidade. Ou períodos simples, principalmente devido ao pouco espaço entre as falas dos personagens".

Mas também pode haver o contrário: duas ou mais frases podem se tornar uma só, para deixar o texto mais conciso. Um procedimento que pode ser feito é, durante a revisão de uma $A-D$, tentar diminuir o número de palavras e/ou caracteres, sem necessariamente diminuir o número de informações presentes na(s) frase(s). Um exemplo hipotético de uma sequência áudio-descritiva de uma cena de filme: "Numa rua ensolarada e deserta, um homem caminha. Ele está alegre e saltitante. O homem é branco e alto". A sequência poderia ser simplificada para "Numa rua ensolarada e deserta, um homem branco e alto anda alegre e saltitante".

O texto da A-D deve estar em concordância com a norma culta. Eventualmente, até os melhores roteiros podem conter algum erro gramatical. Consideramos como "dificuldade", os roteiros que continham muitos erros gramaticais. Foram detectados sete roteiros com excesso de dificuldades gramaticais: erros de digitação, acentuação, concordância nominal, concordância verbal etc. Recomendamos aos alunos, profissionais e consultores de A-D o constante contato com gramáticas e grupos ou blogs de internet dedicados à Língua Portuguesa.

Nos roteiros dos alunos, também encontramos questões gramaticais mais específicas. Em A-D, não há necessidade de usar conjunções adversativas (mas, porém, contudo, todavia...). Houve sete roteiros com a palavra "mas" no texto da A-D. Em todas essas ocorrências, a solução foi simplesmente eliminar a conjunção ou substituí-la por um "e". Alguns exemplos hipotéticos de A-Ds com adversativas: "A blusa é azul, mas com a gola branca" ("A blusa é azul com a gola branca"); "A mulher sorri, mas vira a cabeça para o lado" ("A mulher sorri e vira a cabeça para o lado").

Os roteiros de A-D devem evitar o uso de possessivos (seu, seus, sua, suas), pois podem causar uma ambiguidade no texto. E mesmo que não cause, em nome da 
concisão, o possessivo pode, em geral, ser eliminado ou trocado por um artigo definido. Frases como: "Uma mulher para em frente a uma porta. A sua aparência é robusta". Quem tem aparência robusta, a mulher ou a porta? Ao eliminar o possessivo "sua", a frase poderia ficar "Uma mulher robusta para em frente a uma porta" ou "Uma mulher para em frente a uma porta robusta". Outra frase hipotética: "Um homem anda. A sua mão direita está fechada". Com a eliminação do possessivo "sua", a frase poderia ficar: "Um homem anda. A mão direita está fechada". Constatamos 16 roteiros com várias ocorrências dos possessivos.

Mas não são apenas os possessivos que podem causar ambiguidade. Em outros três roteiros, foram detectados outras ambiguidades; em dois deles, os pronomes pessoais do caso reto de terceira pessoa ("ele" e "ela") foram os responsáveis. De fato, os pronomes ele, eles, ela, elas também podem causar ambiguidade e, por isso, devem ser usados com cautela.

O uso incorreto de artigos foi encontrado em 27 roteiros. Em 25 deles, a principal dificuldade foi o uso dos artigos definidos (o, os, a as) no lugar em que deveria haver o uso dos indefinidos (um, uns, uma, umas). Em dois roteiros, a "dificuldade" foi a ausência dos artigos indefinidos em vários momentos. Como regra geral, os artigos indefinidos devem ser usados para substantivos que não foram mencionados; os artigos definidos se referem a substantivos já mencionados no texto.

Suponhamos que o início de uma $A-D$ de vídeo tenha a frase "O homem anda apressado na rua.”. Duas perguntas vêm à mente: que homem? Que rua? Por não terem sido mencionados anteriormente, "homem" e "rua" devem ser antecedidos por artigo indefinido: "Numa rua, um homem anda apressado". A partir daí, para qualquer menção a esse mesmo homem ou a essa mesma rua, o artigo correspondente será o definido: "a rua", "o homem".

Nos dois roteiros em que houve a omissão dos artigos, percebemos que se tratou de uma estratégia para deixar o texto mais conciso. A omissão se deu em casos em que se deveriam usar os artigos indefinidos. Foram frases como: "Rua. Homem anda". Alguns chamariam essa estratégia de "linguagem telegráfica". A questão é como o público-alvo da A-D concebe essa linguagem telegráfica? Ajuda na construção da imagem mental ou causa algum conflito? Talvez, quando o espaço para a inserção da A-D no vídeo seja pequeno, essa estratégia possa ser usada. Mas recomendamos que, sempre que 
http://dx.doi.org/10.5902/1984686X35720

possível, sejam usadas frases completas, com os devidos artigos: "Em uma rua, um homem anda".

\section{Considerações finais}

Durante as análises dos resultados, sugerimos que os alunos, antes de produzirem o primeiro roteiro de A-D para vídeo, tenham bastante contato com outros roteiros e notas proêmias. No entanto, sabemos da carência de roteiros de A-D acessíveis e disponíveis na internet. Além disso, existe a questão dos direitos autorais: não se pode pegar um roteiro de alguém e usá-lo sem permissão.

Talvez, os próprios profissionais e empresas dedicadas à $A-D$ pudessem disponibilizar alguns de seus roteiros digitados, para fins educacionais. Tal atitude, além de ajudar o aluno principiante, contribuiria para o próprio aperfeiçoamento do profissional responsável pelo roteiro, que poderia receber diferentes feedbacks dos demais profissionais da área.

Temos consciência de que as dificuldades encontradas nos roteiros dos alunos por nós analisados foram, em alguma medida, influenciadas pelo próprio contexto do curso e pelos modelos e diretrizes adotados pela tutoria responsável pelos feedbacks, além da proposta de só se observar aspectos mais básicos do roteiro. As condições em que um principiante produz um roteiro de A-D para vídeos ou filmes por primeira vez podem determinar tipo e quantidade de "dificuldades" presentes no roteiro.

Embora tenhamos feito este estudo em um contexto bastante específico e com um corpus limitado, os dados obtidos nos permite afirmar que há uma tendência de que alunos principiantes apresentem algumas dificuldades similares na primeira produção de um roteiro de A-D para vídeo/filme, constatada, por exemplo, pelo grande número de roteiros com o uso desnecessário dos pronomes possessivos, com o uso incorreto dos artigos e com a produção de textos áudio-descritivos que não cabem dentro do espaço de tempo determinado.

Diante das dificuldades encontradas nos roteiros, algumas das propostas de soluções aqui apresentadas por nós poderiam ser repassadas aos futuros alunos de cursos de A-D, por exemplo, nos enunciados das próprias atividades, nos materiais do curso e/ou em webconferências, caso haja esse recurso. A constatação e a ciência prévias de quais são algumas das dificuldades comumente ocorrentes nos roteiros de A-D de vídeos feitos por principiantes, bem como o oferecimento de suas respectivas 
possíveis soluções, podem ajudar o aluno iniciante em A-D a não apresentar tais dificuldades já desde o primeiro roteiro produzido.

Acreditamos que muitos outros estudos similares precisem ser feitos para se obter resultados mais conclusivos. Por isso, convidamos todos os profissionais e estudiosos da A-D a fazerem mais pesquisas, para que o beneficiário principal, o público-alvo da A-D, possa receber uma A-D empoderativa e de qualidade, dentro de uma sociedade cada vez mais inclusiva.

\section{Referências}

ALVES, Soraya F.; TELES, Veryanne C.; PEREIRA, Tomás V. Propostas para um modelo brasileiro de audiodescrição para deficientes visuais. In: Revista Tradução e

Comunicação. N. 22, 2011. Disponível em:

http://sare.anhanguera.com/index.php/rtcom/article/view/3158/1215. Acesso em: 04 de janeiro de 2017.

AUDIO DESCRIPTION COALITION, Diretrizes para Áudio-Descrição e Código de Conduta Profissional para Áudio-descritores. Trad. VIEIRA, Paulo André de Melo. In:

Revista Brasileira de Tradução Visual, vol.4, 2010. Disponível em

http://www.rbtv.associadosdainclusao.com.br/. Acesso em: 14 de setembro de 2013.

ITC Guidance on Standards for Audiodescription, Audetel, 2000.

JAKOBSON, Roman. Aspectos linguísticos da tradução. Trad. Izidoro Blikstein. Linguística e Comunicação. São Paulo: Cultrix, 1995, pp. 63-86.

LIMA, Francisco J. de. Introdução aos estudos do roteiro para áudio -descrição: sugestões para a construção de um script anotado. In: Revista Brasileira de Tradução Visual, v. 7, 2011. Disponível em http://www.rbtv.associadosdainclusao.com.br/index.php/. Acesso em: 22 de julho de 2014.

LIMA, Francisco J. de. Correta Grafia de Áudio-descrição. Portal Lerparaver, uma janela para o mundo, 05 abr. 2016. Disponível em: http://www.lerparaver.com/lpv/correta-grafiaaudio-descricao. Acesso em: 10 dez. 2017.

LIMA, Francisco J. de; GUEDES, Lívia C.; GUEDES, Marcelo C. Áudio-descrição: orientações para uma prática sem barreiras atitudinais. In: Revista Brasileira de Tradução Visual, 2010. Vol.2. Disponível em:

http://www.associadosdainclusao.com.br/enades2016/sites/all/themes/berry/documentos/0 4-audio-descricao-pratica-sem-barreiras-atitudinais.pdf. Acesso em: 10 de janeiro de 2017.

MIANES, Felipe L. Consultoria em audiodescrição: alguns caminhos e possibilidades. In: CARPES, Daiana Stockey (Org.). Audiodescrição: práticas e reflexões. Santa Cruz do Sul: Catarse, $1^{\text {a }}$ ed., 2016. 
MONTE, Mônica M. Roteirizar, gravar, editar: Os efeitos da edição sobre os filmes audiodescritos exibidos na TV brasileira. In: CARPES, Daiana Stockey (Org.).

Audiodescrição: práticas e reflexões. Santa Cruz do Sul: Catarse, 1ํㅡ ed., 2016.

MOTTA, Livia M. V. de M. A audiodescrição vai à ópera. In: MOTTA, Lívia M. V. de M.; ROMEU FILHO, Paulo (org.). Audiodescrição: transformando imagens em palavras. São Paulo: Secretaria dos Direitos da Pessoa com Deficiência do Estado de São Paulo, 2010.

\section{NAVES, Sylvia R. B. (org.). Guia orientador para acessibilidade de produções} audiovisuais. 2015. Disponível em:

https://www.camara.gov.br/internet/agencia/pdf/guia_audiovisuais.pdf. Acesso em: 08 de janeiro de 2017.

OLIVEIRA JÚNIOR, Juarez N. de; PRAXEDES FILHO, Pedro H. L. - A (não) neutralidade em roteiros de audiodescrição-AD de filmes de curta-metragem via sistema de avaliatividade. In: CARPES, Daiana Stockey (Org.). Audiodescrição: práticas e reflexões. Santa Cruz do Sul: Catarse, $1^{\text {a }}$ ed., 2016.

\section{STANDARDS FOR AUDIO DESCRIPTION AND CODE OF PROFESSIONAL CONDUCT FOR DESCRIBERS. Disponível em: \\ http:audiodescriptioncoalition.org/adc_standards_090615.pdf. Acesso em: 25 de novembro de 2013.}

UNE 153020. Audiodescripción para personas com discapacidad visual. Requisitos para la audiodescripción y elaboración de audioguías, Madrid: AENOR, 2005.

\section{Notas finais}

1 Adotamos a grafia "áudio-descrição" ("áudio-descritor", "áudio-descrever") em consonância com Lima (2016). No entanto, as grafias diferentes em textos citados e reproduzidos de outros autores foram respeitadas e mantidas.

2 Dados obtidos em: http://www.ibge.gov.br/home/estatistica/populacao/censo2010/. Acesso em: 14 nov. 2016.

3 ITC Guidance on Standards for Audio Description. Disponível em: http://www.ofcom.org.uk/static/ archive/itc/itc_publications/codes_guidance/audio_description/index.asp.htm. Acesso em: 20 dez. 2016

4 AENOR UNE 153020. Disponível em: https://www.aenor.es/aenor/normas/normas/fichanorma.asp? codigo=N0032787\#.WHPSINQrKt8. Acesso em: 16 dez. 2016.

${ }^{5}$ AUDIO DESCRIPTION COALITION - Standards for Audio Description and Code of Professional conduct for describers. Disponível em: http://www.nps.gov/hfc/acquisition/pdf/audio-description/shared/attach-a.pdf. Acesso em 14 dez. 2016.

${ }^{6}$ AUDIO DESCRIPTION COALITION, Diretrizes para Áudio-Descrição e Código de Conduta Profissional para Áudio-descritores. Trad. VIEIRA, Paulo André de Melo. Revista Brasileira de Tradução Visual, vol.4, 2010. Disponível em http://www.rbtv.associadosdainclusao.com.br/. Acesso em: 14 set. 2013.

7 Disponível em: https://www.youtube.com/watch?v=zmiHEkMfpvw; publicado em 13 dez. 2013.

${ }^{8}$ Disponível em: https://www.youtube.com/watch?v=pf4Y6gtK_y8; publicado em 12 mar. 2016.

${ }^{9}$ Disponível em: https://www.youtube.com/watch?v=sqFhvDANxto; publicado em 06 abr. 2016. 
http://dx.doi.org/10.5902/1984686X35720

${ }^{10}$ Houve roteiros com mais de uma das dificuldades citadas.

${ }^{11}$ Houve roteiros com mais de uma das dificuldades citadas.

12 Houve roteiros com mais de uma das dificuldades citadas.

13 Decidimos preservar as identidades e os textos dos alunos. Por isso, apresentamos apenas as dificuldades encontradas, sem citações literais das frases produzidas pelos estudantes. Em alguns momentos, optamos por exemplificar as dificuldades com frases hipotéticas semelhantes às encontradas nos roteiros desses alunos.

${ }^{14}$ AUDIO DESCRIPTION COALITION, Diretrizes para Áudio-Descrição e Código de Conduta Profissional para Áudio-descritores, p. 09.

${ }^{15}$ AUDIO DESCRIPTION COALITION, Diretrizes para Áudio-Descrição e Código de Conduta Profissional para Áudio-descritores, p. 33.

\section{Correspondência}

Paulo Augusto Almeida Seemann - ETEC Guaracy Silveira, Escola Técnica Estadual Guaracy Silveira, rua Ferreira de Araújo, n. 527, Pinheiros, São Paulo, São Paulo - Brasil.

CEP: 05428-001

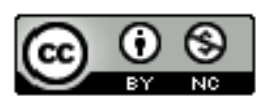

This work is licensed under a Creative Commons Attribution-NonCommercial 4.0 International (CC BY-NC 4.0)

\section{Modalidade do artigo: Relato de pesquisa (X)}

